\title{
Extraskeletal Myxoid Chondrosarcoma: A Clinicopathologic, Immunohistochemical, and Ploidy Analysis of 23 Cases
}

Andre M. Oliveira, M.D., Thomas J. Sebo, M.D., James E. McGrory, M.D., Thomas A. Gaffey, M.D., Michael G. Rock, M.D., Antonio G. Nascimento, M.D.

Department of Laboratory Medicine and Pathology (AMO, TJS, TAG, AGN) and the Department of

Orthopedics (JEM, MGR), Mayo Clinic and Mayo Foundation, Rochester, Minnesota

Twenty-three cases of extraskeletal myxoid chondrosarcoma, evaluated at the Mayo Clinic between 1968 and 1996, were studied for clinicopathologic features, immunohistochemical profile, Ki-67 activity, and ploidy status to identify adverse prognostic factors. Females and males were equally affected, and the median age at diagnosis was 50 years. The tumors were located mainly in the lower extremities $(83 \%)$, and the median tumor size was $9.5 \mathrm{~cm}$. Sixteen tumors showed low cellularity (70\%), and eight tumors had high mitotic activity (more than two per 10 high-power fields). The tumors were immunoreactive for vimentin (89\%), synaptophysin (72\%), epithelial membrane antigen (28\%), and S-100 protein (17\%). Nine tumors were diploid, three aneuploid, and one tetraploid. Mean Ki-67 activity was $11 \%$ (range, 1 to $45 \%)$. The 10 -year overall survival rate was $78 \%$. On univariate analysis, tumor size $\geq 10$ $\mathrm{cm}$, high cellularity, presence of anaplasia or rhabdoid features, mitotic activity more than two per 10 high-power fields, Ki-67 $\geq 10 \%$, and Ki-67 "hot spot" $\geq 25 \%$ were associated with decreased metastasis-free or overall survival. Ploidy status was not associated with any adverse outcome. The presence of any of these adverse prognostic factors can indicate the possibility of a more aggressive behavior in extraskeletal myxoid chondrosarcoma, and a closer follow-up is suggested.

KEY WORDS: Extraskeletal myxoid chondrosarcoma, Immunohistochemistry, Ki-67, Ploidy, Prognostic factors.

Mod Pathol 2000;13(8):900-908

Copyright (C) 2000 by The United States and Canadian Academy of Pathology, Inc.

VOL. 13, NO. 8, P. 900, 2000 Printed in the U.S.A.

Date of acceptance: February 22, 2000.

Address reprint requests to: A.G. Nascimento, M.D., Department of Laboratory Medicine and Pathology, Mayo Clinic, Rochester, MN 55905; e-mail: nascimento.antonio@mayo.edu.
Extraskeletal myxoid chondrosarcoma (EMC) is a rare soft tissue sarcoma that was recognized as a distinct pathologic entity by Stout and Verner in 1953 (1). However, it was not until 1972 that Enzinger and Shiraki (2) defined the clinicopathologic features of EMC, showing a relatively protracted clinical course and a better prognosis than that with conventional bone chondrosarcomas.

In 1992, Saleh et al. (3) reassessed the clinical features of EMC in a series of 10 patients and showed the "indolent but resilient" nature of this neoplasm; 7 of the patients died of tumor up to 17 years after the initial diagnosis. Seven years later, Meis-Kindblom et al. (4) studied a large series of EMCs, most consultation cases, and showed that older age, larger tumor size, and proximal tumor location were associated with decreased survival by multivariate analysis.

The histogenesis of EMC is still a subject of controversy. However, chondroblastic differentiation has been supported by ultrastructural (5-15) and histochemical (16-18) studies. In addition, cytogenetic and molecular analyses have shown that EMC is a distinct entity with the characteristic translocation $\mathrm{t}(9 ; 22)$ involving the EWS gene (22q12) and the TEC gene (9q22) in a majority of the cases (19-29).

We reviewed the clinicopathologic, immunohistochemical, and ploidy features in a series of 23 cases of EMC evaluated at a single institution to identify potential prognostic factors associated with a more aggressive behavior.

\section{MATERIALS AND METHODS}

Twenty-three patients in whom EMC was diagnosed between 1968 and 1996 were included in this study. Eighteen patients with EMC were diagnosed and primarily treated at the Mayo Clinic, and five patients were referred by other institutions for additional treatment or evaluation. Fifteen cases from this series will be described in another article (30). 
TABLE 1. Antibodies Used in This Study

\begin{tabular}{|c|c|c|c|}
\hline Antibody & Type & Source & Dilution \\
\hline Vimentin 3B4 & $\mathrm{M}$ & DAKO & $1: 500$ \\
\hline Desmin Der11 & M & DAKO & $1: 100$ \\
\hline Wide-spectrum keratin & $\mathrm{P}$ & DAKO & $1: 200$ \\
\hline Epithelial membrane antigen (EMA) & M & DAKO & $1: 20$ \\
\hline $\begin{array}{l}\text { Polyclonal carcinoembryonic } \\
\text { antigen (pCEA) }\end{array}$ & $\mathrm{P}$ & DAKO & $1: 800$ \\
\hline S-100 protein & $\mathrm{P}$ & HSC & $1: 2,000$ \\
\hline Synaptophysin SY38 & $\mathrm{M}$ & ICN Biomedicals & $1: 40$ \\
\hline Chromogranin & M & $\begin{array}{l}\text { Boehringer } \\
\text { Mannheim }\end{array}$ & $1: 1,000$ \\
\hline Leu-7 (CD57) & M & Becton Dickinson & $1: 20$ \\
\hline Actin HHF35 (actin muscle-specific) & M & DAKO & $1: 50$ \\
\hline$\alpha$-Smooth muscle actin 1 A4 & M & DAKO & $1: 150$ \\
\hline MIC2 (CD99) & M & DAKO & $1: 50$ \\
\hline Glial fibrillary acid protein (GFAP) & $\mathrm{P}$ & DAKO & $1: 300$ \\
\hline Ki-67 (MIB-1) & $\mathrm{M}$ & Immunotech & $1: 50$ \\
\hline
\end{tabular}

HSC, Hospital for Sick Children; M, monoclonal; P, polyclonal.

Clinical data, including follow-up information, were obtained from medical record review, referring physicians, and telephone survey.

Hematoxylin-eosin-stained archival slides from the primary tumors ( 5 to 21 slides per case; average, 13) were available for review in all cases. The main histologic features investigated were cellularity, mi- totic activity, anaplasia, spontaneous necrosis, and vascular invasion. Cellularity was defined as high when the neoplastic cells represented $75 \%$ or more (and the myxoid matrix represented $25 \%$ or less) of the tumor area within the nodules in at least $25 \%$ of all slides evaluated per tumor. Mitotic count was performed in 10 different high-power fields (HPF, $400 \times$ ) and reported as the number of mitotic figures per $10 \mathrm{HPF}$. Anaplasia was defined as the presence of enlarged and vesicular nuclei with prominent nucleoli in at least $25 \%$ of the tumor area.

Immunohistochemical studies were performed on 4 - $\mu \mathrm{m}$-thick sections of $10 \%$ formalin-fixed, paraffin-embedded tumor material in 18 tumors, according to the avidin-biotin-peroxidase complex system (31). Appropriate positive and negative controls were used for each antibody listed in Table 1. Immunohistochemical analysis addressed the presence or absence of stain in a focal or diffuse pattern. Focal reactivity was defined when less than $25 \%$ of cells were reactive for a specific antibody. Immunoreactivity intensity was not categorized.

Digital image analysis was performed in 13 neoplasms according to a previously described

TABLE 2. Clinical Features of Extraskeletal Myxoid Chondrosarcoma in 23 Patients

\begin{tabular}{|c|c|c|c|c|c|c|c|c|}
\hline Case & $\begin{array}{l}\text { Age } \\
(\mathrm{yr})\end{array}$ & Sex & Location & $\begin{array}{r}\text { Size } \\
(\mathrm{cm})^{*}\end{array}$ & Cellularity & Ploidy & Treatment & Follow-up and Outcome \\
\hline 1 & 47 & M & Thigh, left & 16 & Low & $\mathrm{D}$ & $\mathrm{WLE}+$ postRx & $\begin{array}{l}\text { Lung, sternum, vertebral mets (10 } \\
\text { mo); DOD ( } 23 \mathrm{mo})\end{array}$ \\
\hline 2 & 29 & M & Thigh, left & 18 & Low & $\mathrm{D}$ & $\mathrm{WLE}+$ postRx & Lung mets (9 yr), DOD (22 yr) \\
\hline 3 & 34 & M & $\begin{array}{l}\text { Mets to chest wall, mediastinum, } \\
\text { and lungs (primary tumor: knee, } \\
\text { right) }\end{array}$ & $4 \dagger$ & Low & $\mathrm{D}$ & $\mathrm{ME}+$ postRx & $\begin{array}{l}\text { Knee tumor discovered ( } 4.3 \mathrm{yr}) \text {, } \\
\text { alive }(13 \mathrm{yr})\end{array}$ \\
\hline 4 & 57 & $\mathrm{~F}$ & Ankle, right & 1.5 & Low & $\mathrm{D}$ & WLE & Alive, NED (21 yr) \\
\hline 5 & 27 & M & Ankle, left & 10 & High & $\cdots$ & ME & Alive, NED (6 mo) \\
\hline 6 & 63 & $\mathrm{~F}$ & $\begin{array}{l}\text { Thigh, right with mets to regional } \\
\text { lymph nodes and buttock }\end{array}$ & 4.5 & Low & $\cdots$ & WLE + postRx & Alive with mets ( 1 yr) \\
\hline 7 & 63 & $\mathrm{~F}$ & Thigh, left & 6 & Low & $\cdots$ & WLE & $\begin{array}{l}\text { Local recurrence (8 yr), alive with } \\
\text { NED (20.3 yr) }\end{array}$ \\
\hline 8 & 42 & $\mathrm{~F}$ & Thigh, right & 9 & Low & $\cdots$ & WLE + postRx & Alive, NED (23.5 yr) \\
\hline 9 & 55 & M & Thigh, left & 10 & High & A & WLE & Lung mets (4 mo), DOD (8 mo) \\
\hline 10 & 54 & M & Thigh, right & 10 & High & $\mathrm{T}$ & PreRx + WLE & $\begin{array}{l}\text { Rib and vertebral mets ( } 3.3 \mathrm{yr}) \text {, } \\
\text { DOD ( } 6 \mathrm{yr})\end{array}$ \\
\hline 11 & 50 & $\mathrm{~F}$ & Shoulder, right & 13.5 & High & $\mathrm{D}$ & $\mathrm{WLE}+$ postRx & Lung mets (5.5 yr), DOD (6.8 yr) \\
\hline 12 & 22 & $\mathrm{~F}$ & Shoulder, right & 5 & High & $\cdots$ & WLE & Alive, NED (14.6 yr) \\
\hline 13 & 49 & $\mathrm{~F}$ & Leg, left & 10 & Low & $\cdots$ & WLE & $\begin{array}{l}\text { Lung mets ( } 1.2 \mathrm{yr}) \text {, alive with } \\
\text { mets }(6.5 \mathrm{yr})\end{array}$ \\
\hline 14 & 47 & $\mathrm{~F}$ & Ankle, right & 9 & High & $\mathrm{A}$ & Amputation & Alive, NED (8.2 yr) \\
\hline 15 & 38 & $\mathrm{~F}$ & Chest wall with lung mets & 5 & High & $\mathrm{D}$ & PreChx + WLE & Alive with mets $(7 \mathrm{yr})$ \\
\hline 16 & 52 & M & Thigh, right & 11 & Low & $\cdots$ & $\mathrm{WLE}+$ postRx & $\begin{array}{l}\text { Lung mets }(4 \mathrm{yr}) \text {, alive with mets } \\
(6.8 \mathrm{yr})\end{array}$ \\
\hline 17 & 78 & $\mathrm{~F}$ & Foot, right & 5 & Low & $\mathrm{D}$ & Amputation & Alive, NED (5.5 yr) \\
\hline 18 & 48 & M & Foot, left & 9 & Low & $\mathrm{D}$ & Amputation & Alive, NED (6 yr) \\
\hline 19 & 70 & M & Paravertebral area, left & 5.5 & Low & A & $\mathrm{WLE}+$ postRx & Alive, NED (6.2 yr) \\
\hline 20 & 71 & M & Thigh, left & 18.5 & Low & $\cdots$ & $\begin{array}{l}\text { PreRx }+ \text { WLE }+ \\
\quad \text { postRx }\end{array}$ & $\begin{array}{l}\text { Local recurrence }(3 \mathrm{mo}) \text {, lung } \\
\text { mets }(6 \mathrm{mo}) \text {, alive with mets } \\
(3.3 \mathrm{yr})\end{array}$ \\
\hline 21 & 61 & $\mathrm{~F}$ & Knee, right & 11 & Low & $\mathrm{D}$ & WLE & $\begin{array}{l}\text { Local recurrence ( } 4.8 \mathrm{yr}) \text {, alive } \\
\text { with NED (17 yr) }\end{array}$ \\
\hline 22 & 44 & $\mathrm{~F}$ & Ankle, right & 4 & Low & $\cdots$ & WLE & Alive, NED (13 yr) \\
\hline 23 & 51 & M & Foot, left & 6.5 & Low & $\cdots$ & Amputation & Alive, NED (2 yr) \\
\hline
\end{tabular}

A, aneuploid; D, diploid; ME, marginal excision; mets, metastasis; postRx, postoperative radiotherapy; preChx, preoperative chemotherapy; preRx, preoperative radiotherapy; $\mathrm{T}$, tetraploid; WLE, wide local excision.

* Greatest tumor dimension.

$\dagger$ Knee tumor. 


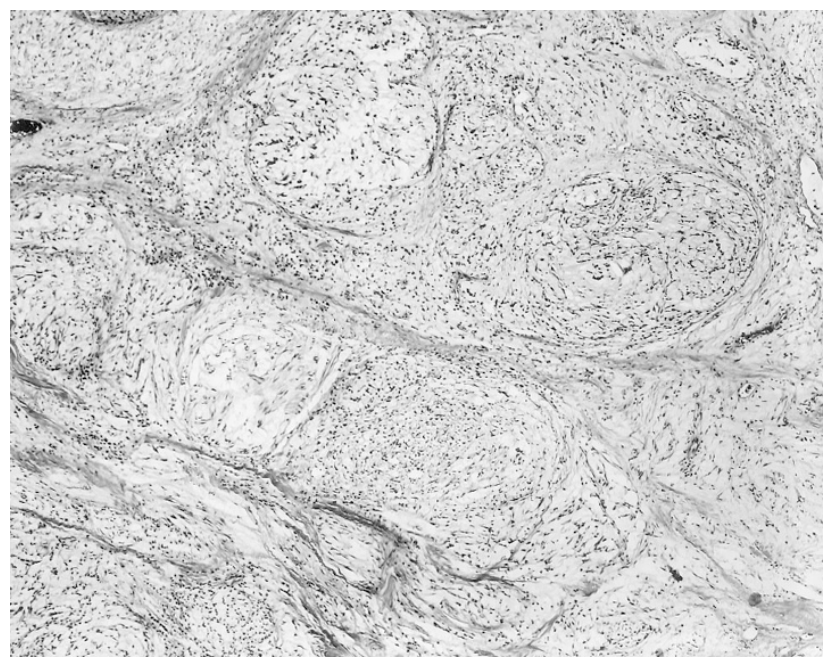

FIGURE 1. Characteristic multilobular architecture of extraskeletal myxoid chondrosarcoma. This was present in all cases.

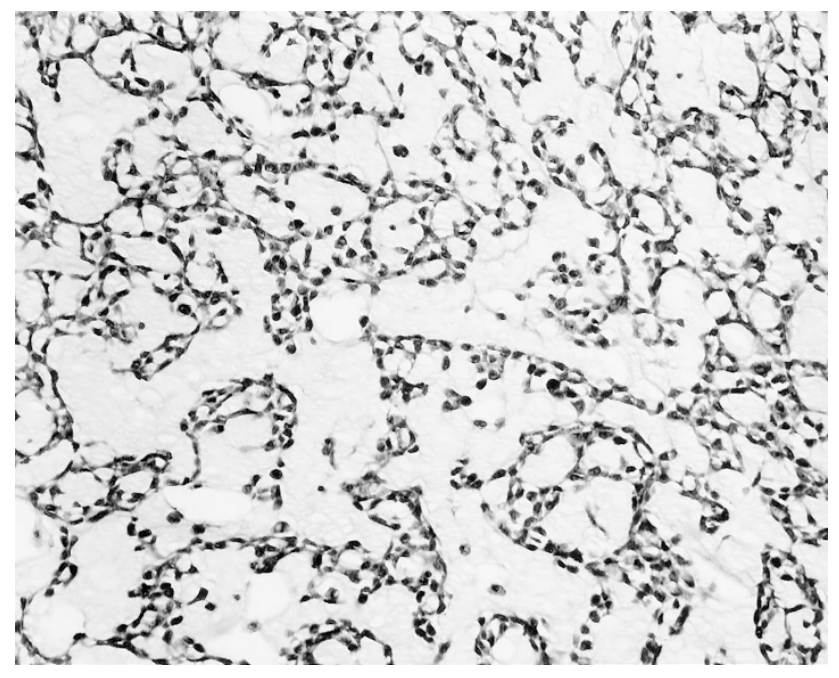

FIGURE 2. Cords and strands of small eosinophilic cells immersed in a myxoid matrix. This is the classic histologic finding in extraskeletal myxoid chondrosarcoma.

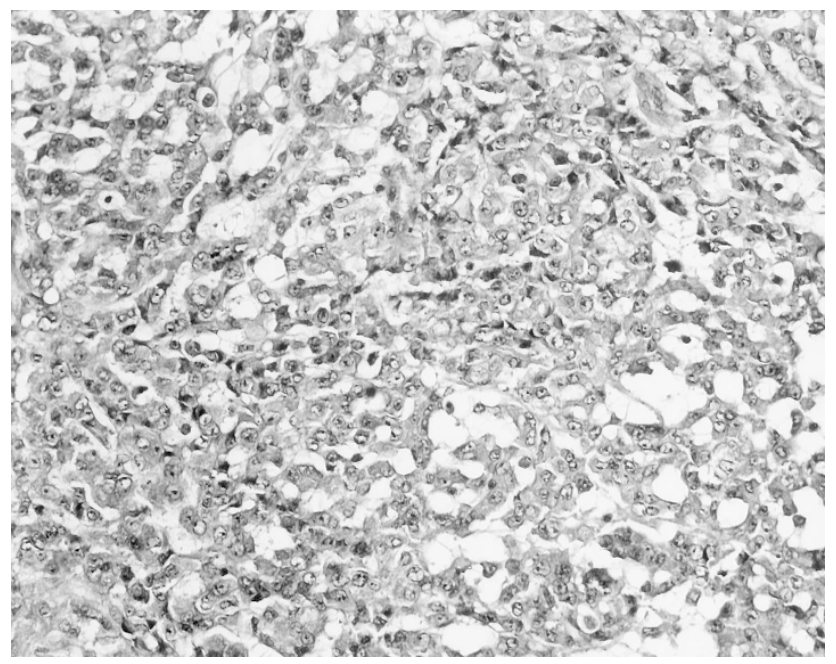

FIGURE 3. Areas composed of large cells with vesicular nuclei and prominent nucleoli were found in three tumors. Interestingly, two of these patients died of disease.

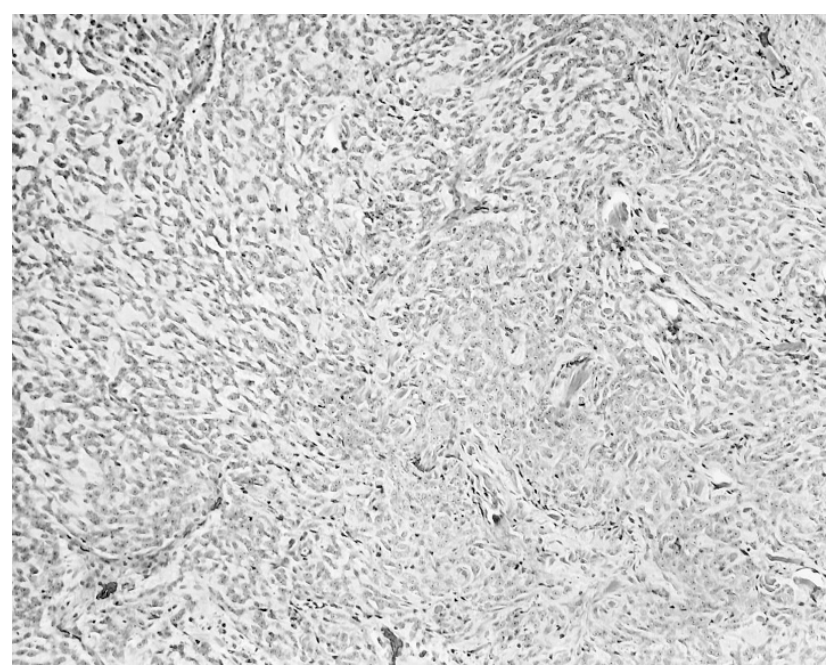

FIGURE 4. High cellularity was present in $30 \%$ of cases and was associated with decreased overall survival by univariate analysis. method (32). An average of 158 cells were counted per tumor (range, 53 to 213 cells). Feulgen stain was used to evaluate tumor ploidy: a DNA index between 0.9 and 1.1 was considered diploid; a DNA index between 1.8 and 2.2 in more than $10 \%$ of the cells was considered tetraploid; and a DNA index between 1.11 and 1.79 or more than 2.2 was considered aneuploid. Immunoperoxidase stain for $\mathrm{Ki}-67$ was used to assess the overall proliferative activity (Table 1). Ki-67 "hot spot" was arbitrarily defined as an area with 25 $\mathrm{mm}^{2}$ around the point with the highest concentration of cells immunoreactive for Ki-67 antigen in the tumor. The total number of cells in this area was counted by digital image analysis, and the percentage of cells immunoreactive for Ki-67 was estimated. This analysis considered that malignant neoplasms are composed of a heteroge- neous population of cells with distinct biological properties $(33,34)$, and this concept has been used in the assessment of microvessel density (35). Therefore, the Ki-67 "hot spot" represented a selection of a group of malignant cells with a high proliferative activity and potentially associated with a more aggressive biological behavior.

Survival of patients with EMC was calculated according to the Kaplan-Meier method (36). Univariate analysis to identify potential prognostic factors associated with metastasis-free and overall survival was performed with the log-rank test (36) and addressed the following variables: age $(\geq$ 45 or $<45$ years), sex (female or male), tumor size ( $\geq 10 \mathrm{~cm}$ or $<10 \mathrm{~cm}$ ), cellularity (high or low), mitotic activity $(>2$ or $\leq 2$ per 10 high-power fields), atypical features (presence of anaplasia or rhabdoid phenotype), Ki-67 expression ( $\geq 10$ or 


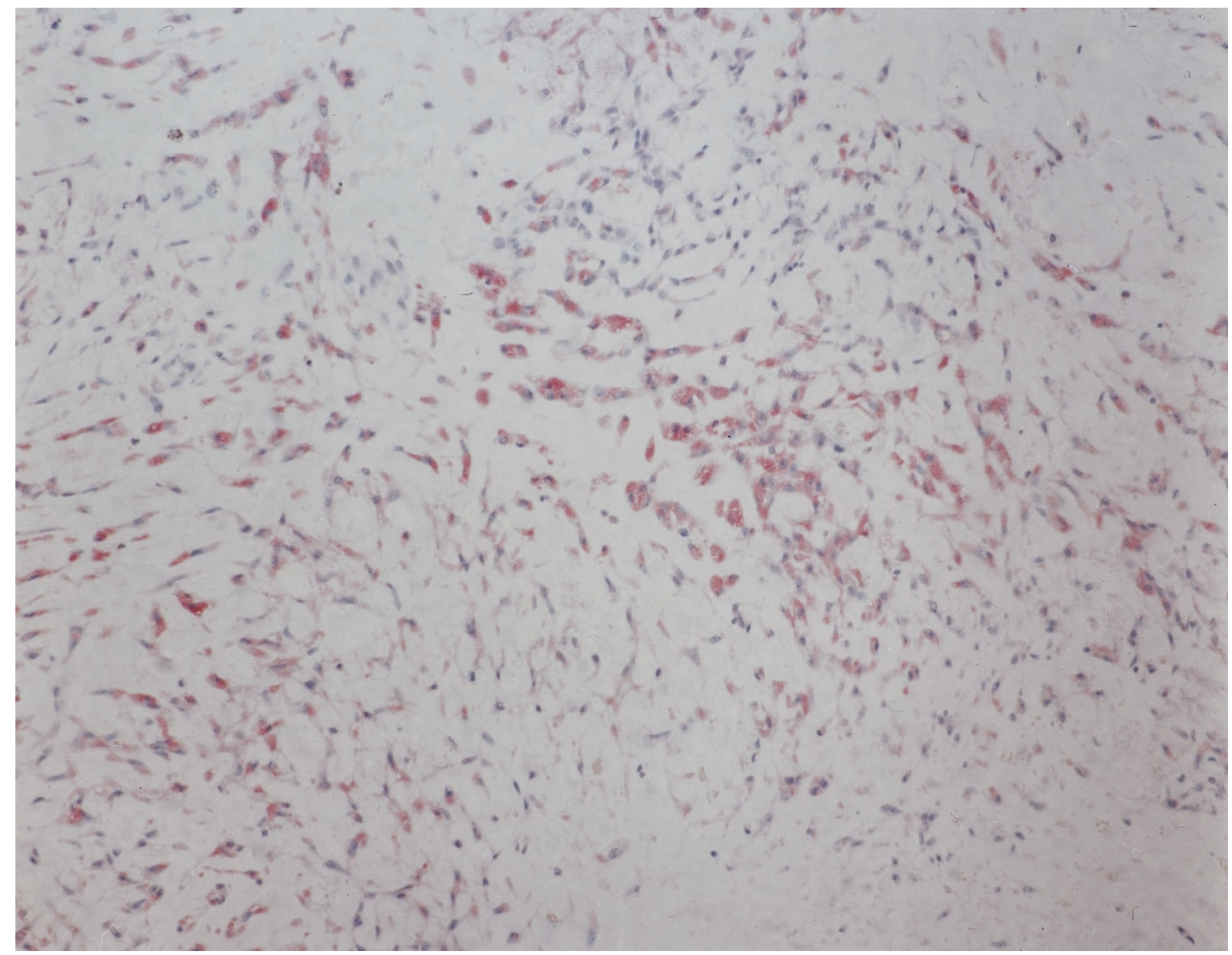

FIGURE 5. Synaptophysin immunoreactivity. This was present in $72 \%$ of the tumors.

TABLE 3. Immunohistochemical Findings in 18 Patients With Extraskeletal Myxoid Chondrosarcoma

\begin{tabular}{|c|c|c|c|c|c|c|c|c|c|c|c|c|c|c|c|c|c|c|}
\hline \multirow{2}{*}{ Marker } & \multicolumn{18}{|c|}{ Case } \\
\hline & 1 & 2 & 3 & 4 & 6 & 9 & 10 & 11 & 13 & 14 & 15 & 16 & 17 & 18 & 19 & 20 & 21 & 23 \\
\hline Vimentin & + & + & + & + & - & + & + & $\mathrm{f}+$ & - & + & + & + & + & + & + & + & + & + \\
\hline Desmin & - & + & - & - & - & - & - & - & - & - & - & - & + & - & - & - & - & - \\
\hline S-100 & - & - & + & - & - & - & - & - & + & + & - & - & - & - & - & - & - & - \\
\hline EMA & - & $\mathrm{f}+$ & - & - & - & + & + & - & - & - & - & + & - & - & + & - & - & - \\
\hline Cytokeratin & - & - & - & - & - & - & - & - & - & - & - & - & - & - & - & - & - & - \\
\hline PCEA & - & - & - & - & - & - & - & - & - & - & - & - & - & - & - & - & - & - \\
\hline Synaptophysin & $\mathrm{f}+$ & $\mathrm{f}+$ & $\mathrm{f}+$ & - & - & $\mathrm{f}+$ & + & + & - & + & $\mathrm{f}+$ & + & - & + & $\mathrm{f}+$ & + & - & + \\
\hline Chromogranin & - & - & - & - & - & - & - & + & - & - & - & - & - & - & - & - & - & - \\
\hline Leu-7 & - & - & - & - & - & - & - & - & - & - & - & + & - & - & - & - & - & - \\
\hline$\alpha$-Smooth muscle actin & - & - & - & - & - & - & - & - & - & - & - & - & - & - & - & - & - & - \\
\hline Actin muscle-specific & - & - & - & - & - & - & - & - & - & - & - & - & - & - & - & - & - & - \\
\hline MIC2 & - & - & - & - & - & - & - & - & - & - & - & - & - & - & - & - & - & - \\
\hline GFAP & - & - & - & - & - & - & - & - & - & - & + & - & - & - & - & - & - & - \\
\hline
\end{tabular}

f, focal.

$<10 \%$ ), Ki-67 "hot spot" expression $(\geq 25 \%$ or $<25 \%$ ), and DNA ploidy (diploid or nondiploid). Vascular invasion and spontaneous necrosis were not evaluated as potential prognostic factors because of the small number of cases in which these features were found. Type of operation (marginal excision, wide local excision, or amputation) and radiotherapy use were excluded from the analysis because of the lack of standardization in the treatment and the small number of cases in our series. Local recurrence was excluded as an end point for survival analysis because of the few events observed (three cases). All $P$ values were two-tailed. 

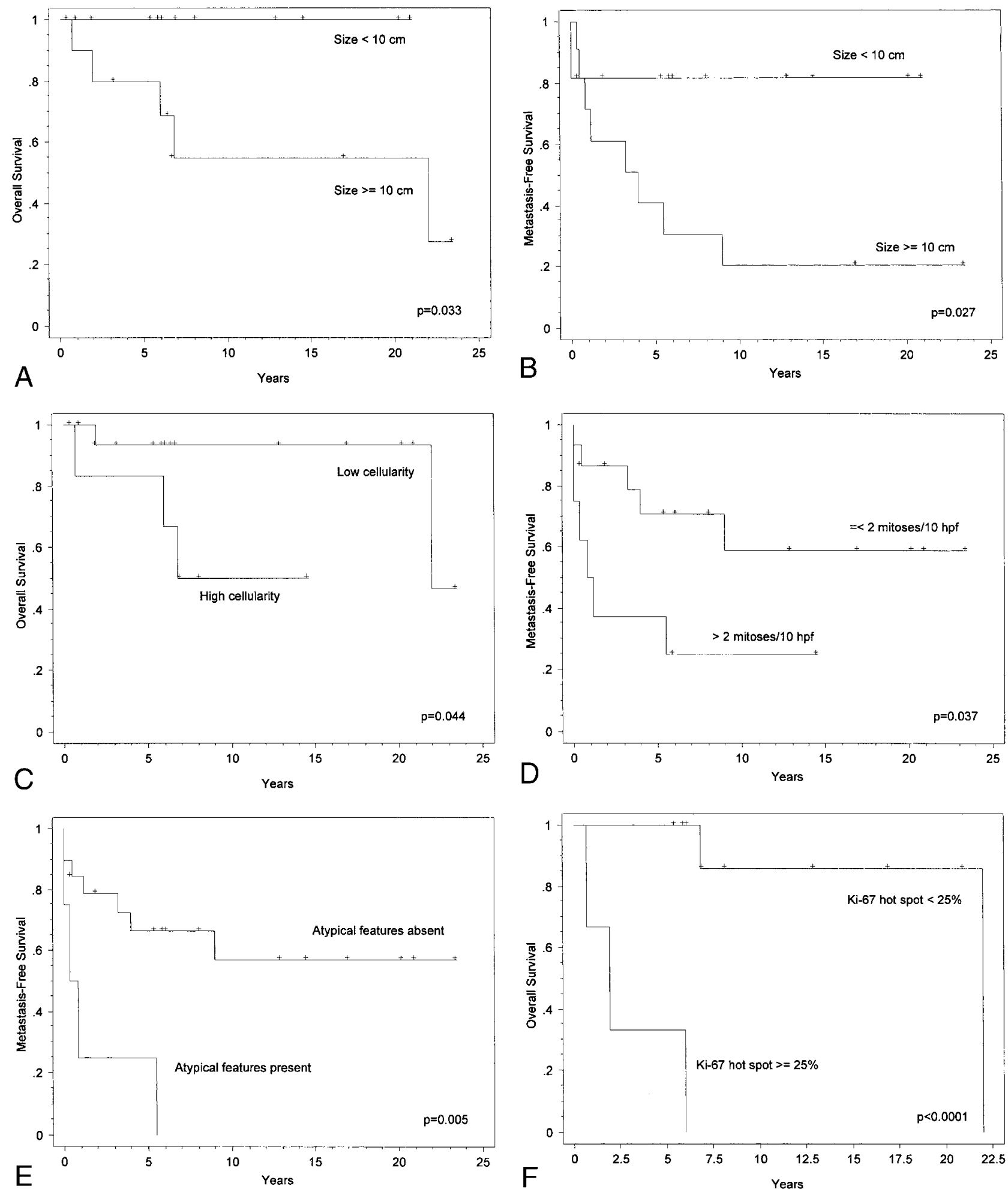

FIGURE 6. Stratified survival curves according to the log-rank test for overall survival and tumor size (A), metastasis-free survival and tumor size (B), overall survival and cellularity (C), metastasis-free survival and mitotic activity (D), metastasis-free survival and atypical features (E), and overall survival and Ki-67 hot spot activity (F).

\section{RESULTS}

\section{Clinical Findings}

Of the 23 patients, 12 were women and 11 were men; their ages ranged from 22 to 78 years (median,
50). The tumors were located in the lower extremities (19 cases, 83\%), upper extremities (two cases), anterior chest wall (one case), and paravertebral area (one case). Among the tumors located in the lower extremities, the thigh was the most common 
TABLE 4. Unfavorable Prognostic Factors in Extraskeletal Myxoid Chondrosarcoma by Univariate Analysis

\begin{tabular}{lcc}
\hline \multicolumn{1}{c}{ Factor } & \multicolumn{2}{c}{$P$ Value } \\
\cline { 2 - 3 } & $\begin{array}{c}\text { Metastasis-free } \\
\text { Survival }\end{array}$ & Overall Survival \\
\hline Age $(\geq 45$ years old) & 0.783 & 0.126 \\
Male sex & 0.077 & 0.068 \\
Tumor $\geq 10 \mathrm{~cm}$ & 0.027 & 0.033 \\
High cellularity & 0.429 & 0.044 \\
Mitotic activity $(>2 / 10$ HPF $)$ & 0.037 & 0.099 \\
Ki-67 $\geq 10 \%$ & 0.012 & 0.563 \\
Ki-67 "hot spot" $\geq 25 \%$ & 0.027 & 0.0001 \\
Nondiploidy & 0.902 & 0.243 \\
Atypical features* & 0.005 & 0.001 \\
\hline
\end{tabular}

* Defined as the presence of anaplasia or rhabdoid phenotype. HPF, high-power field.

anatomical location (nine cases), followed by the ankle (four cases), foot (three cases), knee (two cases), and leg (one case). Twenty-two tumors were deep-seated, and one was subcutaneous (case 4). The duration of symptoms before diagnosis ranged from 1 to 60 mo (median, $6 \mathrm{mo}$ ), and the presence of a palpable mass was the main complaint in all patients but one, who referred to pain only (case 19).

All patients underwent surgical treatment. Wide local excision was performed in 17 patients $(74 \%)$, limb amputation in four (17\%), and marginal excision in two. All margins were considered negative, two after reexcision. Ten patients also received radiation treatment (median dose, 50 Gy). Of these patients, eight received postoperative radiotherapy, one received preoperative and postoperative radiotherapy, and one received preoperative radiotherapy. One patient received preoperative chemotherapy with MAID (combination of mesna, doxorubicin [Adriamycin], ifosfamide, and dacarbazine; case 15). Follow-up information was obtained on all patients, and the duration of follow-up ranged from 0.5 to 23.5 years (mean, 9.3). Three patients presented with metastatic disease (cases 3,6 , and 15) and eight patients had metastasis between 0.3 and 9 years after the initial diagnosis. Metastases were most common in the lungs, followed by bones, lymph nodes, and soft tissues (Table 2). The primary tumor was discovered in one of these patients (case 3) only 4.3 years after the diagnosis of metastatic disease. Local recurrence developed in three patients (cases 20, 21, and 7) 0.25, 4.8, and 8 years after the initial diagnosis, respectively. Five patients (22\%) died of tumor between 0.7 and 22 years after the initial diagnosis; two of these patients had a rapid clinical course, dying in less than 2 years (cases 1 and 9). The remaining 18 patients (78\%) were alive at the end of follow-up, six with metastatic disease (Table 2). The 5-, 10-, and 20-year overall survival rates were $91 \%, 78 \%$, and $78 \%$, re- spectively. The constancy of cumulative survival between 10 and 20 years was due to the lack of tumor-related deaths during this time interval.

\section{Pathologic Findings}

Tumor size ranged from 1.5 to $18.5 \mathrm{~cm}$ (median, 9.5). Macroscopically, the neoplasms were usually described as well-circumscribed, tan-gray, multilobulated, gelatinous masses with focal or extensive hemorrhagic areas.

Histologically, all tumors presented a multinodular architecture and were composed of cords or strands of small cells immersed in a myxoid matrix (Fig. 1 and 2). The cells were ovoid or spindleshaped with a deeply eosinophilic cytoplasm and frequently exhibited hyperchromatic nuclei. Areas composed of large atypical cells with prominent nucleoli were observed in three tumors (cases 1, 3, and 9; Fig. 3). Rhabdoid features were found in two neoplasms (cases 1 and 11). Foci of hyaline cartilage were present in only one neoplasm (case 19); an extensive spindle cell component, fibrosarcomalike, was present in another (case 4). The average mitotic count was usually low, with $61 \%$ of all tumors (14 cases) having less than one mitotic figure per $10 \mathrm{HPF}$. Eight tumors had more than two mitotic figures per $10 \mathrm{HPF}$ (cases 1, 3, 9, 11, 12, 13, 15, and 18). Spontaneous necrosis was identified in two neoplasms (cases 5 and 9). Necrosis was identified in two other neoplasms, but the patients had received preoperative chemotherapy and radiotherapy (cases 15 and 20, respectively). Vascular invasion was detected in three tumors (cases 1, 4, and 18). The surgical margins were negative in all tumors. In two tumors, the margins were considered positive after excisional biopsy but negative after reexcision. The degree of cellularity was considered low in 16 cases (70\%) and high in seven (30\%) according to the criteria described above (Table 2; Fig. 4).

\section{Immunohistochemical Findings}

Vimentin was expressed in 16 cases (89\%). Synaptophysin was expressed in 13 cases (72\%; Fig. 5); focal immunoreactivity was present in six cases. Epithelial membrane antigen (EMA) was expressed in a membrane pattern in five cases (28\%). S-100 protein nuclear immunostaining was detected in only three cases. Desmin was focally expressed in two cases. Immunoreactivity for chromogranin was present in only one tumor (case 11). Leu-7 showed true reactivity in only one case, but a nonspecific background matrix staining was present in eight cases. Focal glial fibrillary acid protein (GFAP) immunoreactivity was identified in case 15 . All tumors lacked immunoreactivity for actin muscle-specific, 
smooth muscle actin, cytokeratin, polyclonal carcinoembryonic antigen (pCEA), and MIC2 (Table 3).

\section{Digital Image Analysis}

Ploidy results by digital image analysis are listed in Table 2. Nine tumors were diploid, three aneuploid, and one tetraploid. Ki-67 activity ranged from 1 to $45 \%$ (mean, $11 \%$ ), and Ki-67 "hot spot" activity ranged from 3 to $49 \%$ (mean, 19\%). High Ki-67 and Ki-67 "hot spot" activities were present in cases 1 ( $45 \%$ and $49 \%$, respectively) and 9 (26\% and $48 \%$, respectively), and both patients died of disease.

\section{Prognostic Factors}

By univariate analysis, tumor size $(\geq 10 \mathrm{~cm})$ and Ki-67 "hot spot" activity ( $\geq 25 \%$ ) correlated with decreased metastasis-free and overall survival (Fig. 6). High cellularity correlated only with decreased overall survival. High mitotic activity (more than two mitotic figures per $10 \mathrm{HPF}$ ) and overall Ki-67 activity $\geq 10 \%$ correlated with decreased metastasis-free survival. Because anaplasia and rhabdoid phenotype were found in a few cases, both features were combined under the term "atypical features" for statistical purposes. The presence of atypical features strongly correlated with metastasis-free and overall survival. A trend to decreased overall survival was observed with high mitotic activity, male sex, and older age, but these features did not reach statistical significance. Ploidy status was not correlated with any adverse outcome (Table 4). The other clinical and histologic factors were not associated with adverse outcomes or could not be analyzed because of the small number of cases studied. Necrosis was excluded as a potential prognostic factor because two of the patients in whom necrosis was found received preoperative radiotherapy or chemotherapy.

\section{DISCUSSION}

Our findings indicate that EMC is usually an indolent tumor and most patients survive for long periods, even in the presence of metastatic disease. However, a few patients can have an aggressive clinical course and die shortly after diagnosis. This is exemplified in two of our cases, and they emphasize the importance of recognizing adverse prognostic factors in EMC to optimize treatment and follow-up.

Because of the small number of patients studied, multivariate analysis for the identification of independent prognostic factors could not be performed. Nonetheless, univariate analysis identified some potential markers. Tumor size was an important prognostic factor, as observed in many other neo- plasms: all patients in our series who died presented with large tumors ( $\geq 10 \mathrm{~cm}$ at diagnosis) and developed metastatic disease. These findings are in agreement with recent studies by MeisKindblom et al. (4), who identified large tumor size as an independent prognostic factor by multivariate analysis.

Some reports have shown that high grade or cellularity is correlated with decreased survival $(2,5$, $16,17,19)$. However, other reports have disregarded these findings $(3,4)$. Meis-Kindblom et al. (4) studied the impact of cellularity (categorized as low, moderate, or high) as a prognostic factor in EMC and did not find any association between this histologic feature and adverse outcomes. However, no specific criteria for this stratification were provided. Judging by the pictures in that study, we compared our high-cellular cases with the high-cellular cases exemplified by those authors. We identified high cellularity and mitotic activity (more than two mitotic figures per $10 \mathrm{HPF}$ ) as potential predictors of an adverse outcome. However, because most of the patients who died of disease or developed metastases had large tumors, the independence of those histopathologic features could not be addressed. Other histologic features that could be associated with adverse outcomes were a rhabdoid phenotype and anaplasia. Rhabdoid cells were present in two neoplasms, and both patients died of disease. Anaplasia was present in three tumors, and two patients died of disease in less than 2 years. These histologic features were combined under the term "atypical features" and strongly correlated with metastasis-free and overall survival. These cases showed striking histologic similarities with those recently described by Lucas et al. (37), and the aggressive clinical behavior observed in our cases supports the impression of those authors.

EMC ploidy profile has not been extensively studied (25), and according to our results EMC may show diploid, tetraploid, or aneuploid DNA contents. However, ploidy status did not seem to correlate with any adverse outcome. Ki-67 overall activity ( $\geq 10 \%$ ) was associated with metastasis-free survival but not overall survival in our series. Similar findings were observed by Meis-Kindblom et al. (4). However, in that study, overall Ki-67 activity (treated as a continuous variable) did not correlate with any adverse event in a multivariate model. High Ki-67 "hot spot" activity ( $\geq 25 \%$ ) correlated with both decreased metastasis-free and overall survival. The association between the Ki-67 activity in the "hot spot" area and an adverse prognosis suggests that subclones of cells in EMC with a high proliferative rate might have a high metastatic potential, dictating the overall prognosis $(33,34)$.

Between 18 and $60 \%$ of EMCs express EMA $(4,15$, 19,38 ). In our series, a distinct membrane staining 
was present in only five tumors (28\%). In contrast, none of the tumors were immunoreactive for cytokeratin, which has been previously demonstrated by other authors in a few cases of EMC $(4,39-42)$. These results indicate that the meaning of EMA immunoreactivity needs further elucidation in regard to epithelial differentiation. More importantly, EMA immunoreactivity in EMC may be a problem in the differential diagnosis with other tumors with "chordoid" features, such as chordomas, chondroid chordomas, meningiomas with chordoid features, myoepitheliomas, and chondroid syringomas (15, 42-46). In this regard, clinical information, including tumor location, and negative immunostainings for cytokeratin and actin support the diagnosis of EMC. In addition, a clear membranous epithelial membrane antigen immunoreactivity in EMC occurs in a minority of cases. In meningiomas, epithelial membrane antigen immunoreactivity is usually diffuse and present in almost all cases.

Neuroendocrine differentiation has been reported in tumors with histologic and molecular features of EMC by Chhieng et al. (46a). Immunoreactivity for synaptophysin was identified in $72 \%$ of the 18 tumors evaluated, and one of these tumors also coexpressed chromogranin. Synaptophysin is a 38-kd transmembrane calcium-binding glycoprotein typically found in neuronal presynaptic vesicles $(47,48)$ and is expressed by neuroendocrine and neuroectoderm-derived cells $(49,50)$. Synaptophysin has been shown to be a useful marker of neuroendocrine differentiation when the monoclonal antibody SY38 is used (50). Furthermore, in tissues fixed in formalin, synaptophysin expression can be attenuated, decreasing its sensitivity (51). Chromogranins are a group of acidic proteins present in neurosecretory granules (52) and expressed by most types of neuroendocrine tumors (53). Chromogranin A is widely distributed in neuroendocrine tissues, but its expression depends on the number of neuroendocrine granules present in the cells. Cells with few neuroendocrine granules may show false-negative immunostaining, and this has been demonstrated by variable expression of this marker in small cell carcinomas of the lung, neuroblastomas, Merkel cell carcinomas, and a few other tumors (54). Our results not only support the observations of Chhieng et al. but also show that neuroendocrine differentiation is common in EMC.

Our study indicated that EMC is frequently indolent and is associated with long-term survival, even with metastatic disease. However, an aggressive clinical course occurs in a few cases. Large tumor size, high cellularity, anaplasia or rhabdoid features, high Ki-67 expression, and high mitotic activity seem to be associated with adverse outcomes, but the independence of these clinicopathologic features in relationship to the prognosis could not be addressed. In this regard, we suggest a closer follow-up for patients with any of these features.

Acknowledgments: The authors would like to thank Patricia L. Kasey (Anatomic Pathology), Barbara G. Crawford (Immunostaining Laboratory), and Darren L. Riehle (Digital Morphometric Laboratory), Mayo Clinic, Rochester, MN.

\section{REFERENCES}

1. Stout AP, Verner EW. Chondrosarcoma of the extraskeletal soft tissues. Cancer 1953;6:581-90.

2. Enzinger FM, Shiraki M. Extraskeletal myxoid chondrosarcoma. An analysis of 34 cases. Hum Pathol 1972;3:421-35.

3. Saleh G, Evans HL, Ro JY, Ayala AG. Extraskeletal myxoid chondrosarcoma. A clinicopathologic study of ten patients with long-term follow-up. Cancer 1992;70:2827-30.

4. Meis-Kindblom JM, Bergh P, Gunterberg B, Kindblom LG. Extraskeletal myxoid chondrosarcoma: a reappraisal of its morphologic spectrum and prognostic factors based on 117 cases. Am J Surg Pathol 1999;23:636-50.

5. Dardick I, Legace R, Carlier MT, Jung RC. Chordoid sarcoma (extraskeletal myxoid chondrosarcoma). Virchows Arch A Pathol Anat Histopathol 1983;399:61-78.

6. DeBlois G, Wang S, Kay S. Microtubular aggregates within rough endoplasmic reticulum: an unusual ultrastructural feature of extraskeletal myxoid chondrosarcoma. Hum Pathol 1986;17:469-75.

7. Insabato L, Terracciano LM, Boscaino A, Mozzi RA, Angrisani P, Pettinato G. Extraskeletal myxoid chondrosarcoma with intranuclear vacuoles and microtubular aggregates in the rough endoplasmic reticulum. Report of a case with fine needle aspiration and electron microscopy. Acta Cytol 1990; 34:858-62.

8. Martinez-Tello FJ, Navas-Palacios JJ. Ultrastructural study of conventional chondrosarcomas and myxoid- and mesenchymal-chondrosarcomas. Virchows Arch A Pathol Anat Histol 1982;396:197-211.

9. Mehio AR, Ferenczy A. Extraskeletal myxoid chondrosarcoma with "chordoid" features (chordoid sarcoma). Am J Clin Pathol 1978;70:700-5.

10. Pardo-Mindan FJ, Guillen FJ, Villas C, Vazquez JJ. A comparative ultrastructural study of chondrosarcoma, chordoid sarcoma, and chordoma. Cancer 1981;47:2611-9.

11. Povysil C, Matejovsky Z. A comparative ultrastructural study of chondrosarcoma, chordoid sarcoma, chordoma and chordoma periphericum. Pathol Res Pract 1985;179:546-59.

12. Suzuki T, Kaneko H, Kojima K, Takatoh M, Hasebe K. Extraskeletal myxoid chondrosarcoma characterized by microtubular aggregates in the rough endoplasmic reticulum and tubulin immunoreactivity. J Pathol 1988;156:51-7.

13. Tsuneyoshi M, Enjoji M, Iwasaki H, Shinohara N. Extraskeletal myxoid chondrosarcoma: a clinicopathologic and electron microscopic study. Acta Pathol Jpn 1981;31:439-47.

14. Weiss SW. Ultrastructure of the so-called "chordoid sarcoma." Evidence supporting cartilagenous differentiation. Cancer 1976;37:300-6.

15. Wick MR, Burgess JH, Manivel JC. A reassessment of "chordoid sarcoma." Ultrastructural and immunohistochemical comparison with chordoma and skeletal myxoid chondrosarcoma. Mod Pathol 1988;1:433-43.

16. Fletcher CD, McKee PH. Immunohistochemistry and histogenesis of extraskeletal myxoid chondrosarcoma [letter]. J Pathol 1985;147:67-8.

17. Fletcher CD, Powell G, McKee PH. Extraskeletal myxoid chondrosarcoma: a histochemical and immunohistochemi- 
cal study. Histopathology 1986;10:489-99.

18. Kindblom LG, Angervall L. Myxoid chondrosarcoma of the synovial tissue. A clinicopathologic, histochemical, and ultrastructural analysis. Cancer 1983;52:1886-95.

19. Antonescu CR, Argani P, Erlandson RA, Healey JH, Ladanyi M, Huvos AG. Skeletal and extraskeletal myxoid chondrosarcoma: a comparative clinicopathologic, ultrastructural, and molecular study. Cancer 1998;83:1504-21.

20. Brody RI, Ueda T, Hamelin A, Jhanwar SC, Bridge JA, Healey $\mathrm{JH}$, et al. Molecular analysis of the fusion of EWS to an orphan nuclear receptor gene in extraskeletal myxoid chondrosarcoma. Am J Pathol 1997;150:1049-58.

21. Clark J, Benjamin H, Gill S, Sidhar S, Goodwin G, Crew J, et al. Fusion of the EWS gene to CHN, a member of the steroid/ thyroid receptor gene superfamily, in a human myxoid chondrosarcoma. Oncogene 1996;12:229-35.

22. Hinrichs SH, Jaramillo MA, Gumerlock PH, Gardner MB, Lewis JP, Freeman AE. Myxoid chondrosarcoma with a translocation involving chromosomes 9 and 22. Cancer Genet Cytogenet 1985;14:219-26.

23. Hirabayashi Y, Ishida T, Yoshida MA, Kojima T, Ebihara Y, Machinami R, et al. Translocation $(9 ; 22)(\mathrm{q} 22 ; \mathrm{q} 12)$. A recurrent chromosome abnormality in extraskeletal myxoid chondrosarcoma. Cancer Genet Cytogenet 1995;81:33-7.

24. Labelle Y, Zucman J, Stenman G, Kindblom LG, Knight J, Turc-Carel C, et al. Oncogenic conversion of a novel orphan nuclear receptor by chromosome translocation. Hum Mol Genet 1995;4:2219-26.

25. Orndal C, Carlen B, Akerman M, Willen H, Mandahl N, Heim $\mathrm{S}$, et al. Chromosomal abnormality $\mathrm{t}(9 ; 22)(\mathrm{q} 22 ; \mathrm{q} 12)$ in an extraskeletal myxoid chondrosarcoma characterized by fine needle aspiration cytology, electron microscopy, immunohistochemistry and DNA flow cytometry. Cytopathology 1991;2:261-70.

26. Sciot R, Dal Cin P, Fletcher C, Samson I, Smith M, De Vos R, et al. $\mathrm{t}(9 ; 22)(\mathrm{q} 22-31 ; \mathrm{q} 11-12)$ is a consistent marker of extraskeletal myxoid chondrosarcoma: evaluation of three cases. Mod Pathol 1995;8:765-8.

27. Stenman G, Andersson H, Mandahl N, Meis-Kindblom JM, Kindblom LG. Translocation $\mathrm{t}(9 ; 22)(\mathrm{q} 22 ; \mathrm{q} 12)$ is a primary cytogenetic abnormality in extraskeletal myxoid chondrosarcoma. Int J Cancer 1995;62:398-402.

28. Turc-Carel C, Dal Cin P, Rao U, Karakousis C, Sandberg AA. Recurrent breakpoints at 9q31 and 22q12.2 in extraskeletal myxoid chondrosarcoma. Cancer Genet Cytogenet 1988;30: $145-50$.

29. Rubin BP, Fletcher JA. Skeletal and extraskeletal myxoid chondrosarcoma: related or distinct tumors? Adv Anat Pathol 1999;6:204-12.

30. McGrory JE, Rock MG, Nascimento AG, Oliveira AM. Extraskeletal myxoid chondrosarcoma. Clin Orthop (in press).

31. Hsu SM, Raine L, Fanger H. Use of avidin-biotin-peroxidase complex $(\mathrm{ABC})$ in immunoperoxidase techniques: a comparison between $\mathrm{ABC}$ and unlabeled antibody (PAP) procedures. J Histochem Cytochem 1981;29:577-80.

32. Hedley DW, Shankey TV, Wheeless LL. DNA cytometry consensus conference. Cytometry 1993;14:471.

33. Nowell PC. The clonal evolution of tumor cell populations. Science 1976;194:23-8.

34. Klein G, Klein E. Evolution of tumours and the impact of molecular oncology. Nature 1985;315:190-5.

35. Salvesen HB, Iversen OE, Akslen LA. Prognostic significance of angiogenesis and $\mathrm{Ki}-67, \mathrm{p53}$, and $p 21$ expression: a population-based endometrial carcinoma study. J Clin Oncol 1999;17:1382-90.

36. Klein JP, Moeschberger ML. Statistics for biology and health. Survival analysis: techniques for censored and truncated data. New York: Springer-Verlag; 1997.

37. Lucas DR, Fletcher CD, Adsay NV, Zalupski MM. High-grade extraskeletal myxoid chondrosarcoma: a high-grade epithelioid malignancy. Histopathology 1999;35:201-8.

38. Dei Tos AP, Wadden C, Fletcher CDM. Extraskeletal myxoid chondrosarcoma: an immunohistochemical reappraisal of 39 cases. Appl Immunohistochem 1997;5:73-7.

39. Abramovici LC, Steiner GC, Bonar F. Myxoid chondrosarcoma of soft tissue and bone: a retrospective study of 11 cases. Hum Pathol 1995;26:1215-20.

40. Klijanienko J, Micheau C, Cote R, Flamant F, Caillaud JM. Unusual extraskeletal myxoid chondrosarcoma in a child. Histopathology 1990;16:196-8.

41. Michal M, Dedic K. Embryonal form of extraskeletal myxoid chondrosarcoma with intermediate filament positive hyaline-like globules. Zentralbl Pathol 1992;138:312-5.

42. O’Hara BJ, Paetau A, Miettinen M. Keratin subsets and monoclonal antibody HBME-1 in chordoma: immunohistochemical differential diagnosis between tumors simulating chordoma. Hum Pathol 1998;29:119-26.

43. Ferreiro JA, Nascimento AG. Hyaline-cell rich chondroid syringoma. A tumor mimicking malignancy. Am J Surg Pathol 1995;19:912-7.

44. Ishida T, Oda H, Oka T, Imamura T, Machinami R. Parachordoma: an ultrastructural and immunohistochemical study. Virchows Arch A Pathol Anat Histopathol 1993;422:239-45.

45. Kilpatrick SE, Hitchcock MG, Kraus MD, Calonje E, Fletcher CD. Mixed tumors and myoepitheliomas of soft tissue: a clinicopathologic study of 19 cases with a unifying concept. Am J Surg Pathol 1997;21:13-22.

46. Nagao T, Sugano I, Ishida Y, Tajima Y, Matsuzaki O, Konno A, et al. Salivary gland malignant myoepithelioma: a clinicopathologic and immunohistochemical study of ten cases. Cancer 1998;83:1292-9.

46a.Chhieng DC, Erlandson RA, Antonescu C, Ladany M, Rosai J. Neuroendocrine differentiation in adult soft tissue sarcomas with features of extraskeletal myxoid chondrosarcoma: Report of seven cases [abstract]. Mod Pathol 1998;11:8A.

47. Thomas L, Hartung K, Langosch D, Rehm H, Bamberg E, Franke WW, et al. Identification of synaptophysin as a hexameric channel protein of the synaptic vesicle membrane. Science 1988;242:1050-3.

48. Wiedenmann B, Franke WW, Kuhn C, Moll R, Gould VE. Synaptophysin: a marker protein for neuroendocrine cells and neoplasms. Proc Natl Acad Sci U S A 1986;83:3500-4.

49. Gould VE. Synaptophysin. A new and promising panneuroendocrine marker. Arch Pathol Lab Med 1987;111: 791-4.

50. Gould VE, Wiedenmann B, Lee I, Schwechheimer K, Dockhorn-Dworniczak B, Radosevich JA, et al. Synaptophysin expression in neuroendocrine neoplasms as determined by immunocytochemistry. Am J Pathol 1987;126:243-57.

51. Hoog A, Gould VE, Grimelius L, Franke WW, Falkmer S, Chejfec G. Tissue fixation methods alter the immunohistochemical demonstrability of synaptophysin. Ultrastruct Pathol 1988;12:673-8.

52. Lloyd RV. Immunohistochemical localization of chromogranin in normal and neoplastic endocrine tissues. Pathol Annu 1987;22:69-90.

53. Larsson L, Alumets J, Eriksson B, Håkanson R, Lundquist G, Öberg K, et al. Antiserum directed against chromogranin A and $\mathrm{B}(\mathrm{CAB})$ is a useful marker for peptide hormoneproducing endocrine cells and tumors. Endocr Pathol 1992; 3:14-22.

54. Chaiwun B, Cote RJ, Taylor CR. Diffuse neuroendocrine and endocrine systems. Major Probl Pathol 1994;19:163-99. 